\title{
The Impact of Creativity on Zain Mobile Telecommunication Company of Jordan: An Empirical Analytical Study
}

\author{
Hesham Shatnawi ${ }^{1}$ \\ ${ }^{1}$ The Faculty of Management-National Ajloun University, Jordan \\ Correspondence: Hesham Shatnawi, The Faculty of Management-National Ajloun University, Jordan. E-mail: \\ Shatnawi_hisham@yahoo.com
}

Received: May 11, 2015

Accepted: June 15, 2015

Online Published: August 22, 2015

doi:10.5539/ijbm.v10n9p251

URL: http://dx.doi.org/10.5539/ijbm.v10n9p251

\begin{abstract}
The study aimed to identify the impact of creativity on learning organization, the reasons and obstacles that prevent the ability of Arabian organizations to manage creativity for the employees and the role of creativity and connecting it with the process of organizational leaning through the change environment.

To achieve the objective of the study, a questionnaire has been developed and distributed on (100) employees working at Zain communication company. They were represented the sample of the study reached for achieving the objectives by verifying the hypothesis after applying the appropriate statistical methods, and the statistical significant. The study has reached to empirical results that represent the contribution that came in the study singled out.

1) There is a statically significant at $(\alpha=0.05)$ between creativity management and successfulness of learning organization.

2) There is a statically significant at $(\alpha=0.05)$ between creativity management and the availability of establishing the learning organization elements.

3) There are no differences in thoughts of sample individuals about the impact of creativity management in the learning organizations according to (experience, scientific qualification, and the managerial level).

The study has recommended in:

1) Encouraging the learning organizations on competition and developing the spirit of creativity and productivity.

2) Encouraging the employers of the learning organizations to introduce improving ideas to develop the institutions.

3) Involving with the employers in making decisions at the learning organizations.
\end{abstract}

Keywords: learning organization, creativity, telecommunication company, Jordan

\section{Introduction}

In the advanced countries, the researchers are interested in the concept of learning organization. It is considered one of the most important subject in the modern managing thought. The learning organization can be defined as "the skillful organization that helps in creating, transferring, and gaining the knowledge. It is the organization that establishes cultural basics to support the process of the continuous learning and the adoption process to achieve the objectives of the organization and the needs of the employees. It is also identified as "the organization that seeks for continues learning and achieving the quality through the importance of teaching and learning".

It is the organization that seeks for developing its capability to adopt, and the continuous change by effective workers doing an important role in processing the issues of the organization and believing that learning is the way to adjust and making the development and solving the problems. Moreover, it is a necessity for making continues development for the organization to grantee its future and stability.

The first who has spoken about the basics and theories of the learning organization is (Simon) in his book the managerial behavior in 1975. After (Simon) many scientists as (Sims, Biddler, Stata, Seeing, Jarfen, \& arcoardat) 
in 1980s led the features of this theory which release the most important source to achieve the effectiveness in the organizations and how to deal with the demands of the changeable environment, and managing the mental abilities of the people.

\subsection{The Problem of the Study}

The main problem of this study is to look at the reasons and obstacles that prevent the Arabian organization to manage the creativity with the employers. Also, the role of creativity on these organizations through dynamic and present environment.

\subsection{The Importance of the Study}

It is a significant study, because it is consisted of the main subjects that are considered important in the modern researches and they are: creativity, the learning organization, and to link creativity with the process of the organizational learning through the conditions of the changeable environment.

\subsection{The Objectives of the Study}

1) Providing a theoretical framework about the learning organization and improving the phase of reativity management.

2) Identifying the availability of learning organization elements in the community of the study.

3) Identifying if there is a relation among the elements of learning environment and creativity in.

4) Identifying the impact of creativity management to make the learning organization successful through the community of the study.

\subsection{The Questions of the Study}

1) What is the availability of learning organization elements in the community of the study?

2) What is the degree of creativity management in the community of the study?

3) What are the elements of learning organization and the impact of creativity?

\subsection{The Hypothesis of the Study}

1) There is a statically significant between creativity management and the successfulness of learning environment.

2) There is a statically significant between creativity management and availability of establishing the learning organization.

3) There is a difference among the thoughts of the individuals of the study about the impact of creativity management in learning organization according to (gender, experience, scientific qualification, and management level).

\subsection{Method}

The approach of analytical descriptive approach will be used to fit the nature of the study and the method of collecting the data through preparing an questionnaire for that matter.

\section{Literature Review}

\subsection{The Arabian Studies}

The Study of (Hyjan, 1999) (the obstacles of creativity in the Saudi Arabia government organizations): It was included (68) government institutions, and aimed to identify obstacles of creativity in Saudi Arabia organizations. The results have shown: the significant differences among the obstacles of creativity and variation Job Titles for managers and personal variables differences for them. It is also proved the existence of obstacles to enable individuals to show what they have from creative capabilities due to various factors including: unprofessional innovators.

The study of (AL-Qabsi, 2002) (The reality of managerial creativity in the public departments in Abu-Dhabi): The study aimed to identify the factors that disable the creativity process of the employers who work in the public departments in Abu-Dhabi and the impact of the personal and hiring factors on the degree of creativity development. The results of the study have shown: high depending on the experts, worry from failing, and the absence of freedom and they are considered the most important factors of preventing creativity with the workers.

The study of (Bkar, 2003) (creativity management in the learning organization at Yarmouk University): The study aimed to identify the existence of the appropriate elements to establish the learning organization (the 
motivations, the aims, the questioning, empowering, properties authorization, evaluation, and reviewing). The results of the study have shown: there is existence for the elements of learning organization, and there is a positive relation between the elements of the organization and creativity.

The study of (Abu-Leila, 2007) (the obstacles of creative process in the organizations of small and middle business in Jordan): The study aimed to identify the impact of (gender, qualification, and the years of experience) on the extant availability of the factors of the creative process. The results of the study have shown: the degree of the factors of the creative process was low. Also, the organizations seek to provide the factors of the organizational culture that support the creative process with middle degree.

\subsection{The Foreign Studies}

The study of (Hsu, 2007) (the impact of creativity on the professional institutions): The study aimed to know the behaviors of the workers and the impact of creativity on the people, the organizations, and the communities. The results have shown: the self-sufficient of the workers has a direct effect on creativity.

The study of (Lin, 2008) (the impact of creativity among the organizational departments) in five industrial and technological firms: The study aimed to identify the role of creativity on motivating the competition among the organizational departments. The results of the study have shown that trust and commitment among these departments are considered the main factors for creativity. Also, to identify that honest competition support the activities of the organization and aid the departments to exert the efforts and the interaction process among them.

The study of (Law \& Ngai, 2008) (creativity and improvement the business): The study was applied on the commercial firms and aimed to identify the role of creativity in improving the business of these firms. The results have shown: there is a positive relation between the level of improvement the business and creativity. Moreover the process of improving business and services related positively with creativity.

The study of (Yang, 2009) (creativity, information, and employers): The study aimed to know how the workers are processing the available information and the degree of creativity to be utilized after gathering and analyzing. The results of the study have shown that there are two important factors including the situation of the individual from learning and involving in creativity with others and they have a great impact in processing the information creatively.

So, the main results of these studies show that the concept of learning organization still new, and there is uniqueness in the studies that discuss the subject of creativity management on the organizational level. The majority of the studies constrained on the obstacles of creativity and trying to identify the nature of learning on the learning organizations.

\section{The Community and the Sample of the Study}

The community of the study was consisted of a group of employers who work in "Zain" in different managerial levels. (100) questionnaires were randomly distributed, and the retrieval was (80) and (77) questionnaires were appropriate for statically analysis.

\section{- The tool of the study}

The researcher designed a questionnaire divided into:

First: the personal (demographic) information of the individuals of the study.

Second: (30) paragraphs distributed on the areas of the study and they were seven.

\section{- Verifying the tool of the study}

The study has introduces to a group of expert and specialized judges to verify from the language of the tool and if the paragraphs fit all dimensions and fields of creativity and learning organizations. It has been justified correctly.

\section{The independent variable:}

Managing creativity in the organization.

\section{The fallowing variables:}

The personal empowering, the personal vision, the mental patterns, learning the difference, the organizational thinking.

\subsection{The Statically Processing}

(SPSS) program was applied to process data. The frequencies, percentages, means, and standard deviation were 
extracted."Multiple Regression", "One Sample T-Test”, and “Anova” were applied.

\subsection{The Results of the Statically Analysis and Examining the Hypothesis}

The study aimed to identify the impact of creativity in the learning organizations. The results of the analysis by depending on the hypothesis. This part is including description of individuals according to the personal variables. The results are discussing as the fallowing:

\subsubsection{The Sample of the Study}

The sample of the study was consisted of (77) employers from both genders who work in "Zain" as it is a learning organization. Table 1 shows distributing the individuals of the sample according to the variable of gender. Table 1 shows that number of males was (50) and the percentage (64.9\%), whereas female (27) and the percentage (35.1\%).

Table 1. Distributing the individuals of the sample according to variable of gender

\begin{tabular}{lll}
\hline Gender & frequency & percentage \\
\hline Male & 50 & $64.9 \%$ \\
Female & 27 & $35.1 \%$ \\
Total & 77 & $100 \%$ \\
\hline
\end{tabular}

Table 2 shows that percentage of distributing individuals of the sample according to marital status (single) was $(40.3 \%)$, whereas the percentage of distributing individuals of the sample according to marital status (married) was $(59.4 \%)$.

Table 2. Distributing the individuals of the sample according to marital status

\begin{tabular}{lll}
\hline Marital status & frequency & Percentage \\
\hline Single & 31 & $40.3 \%$ \\
Married & 46 & $59.7 \%$ \\
Total & 77 & $100 \%$ \\
\hline
\end{tabular}

Table 3 shows that the highest percentage for distributing the individuals of the study according to variable of gender $(37.7 \%)$ for the category $(20-30)$ years, and then $(35.1 \%)$ for $(31-40)$ years, next $(23.4 \%)$ for $(41-50)$ years. Whereas the lowest percentage was $(3.9 \%)$ for (above 51$)$ years.

Table 3. Distributing the individuals of the sample according to the variable of age

\begin{tabular}{lll}
\hline Age & Frequency & Percentage \\
\hline $20-30$ years & 29 & $37.7 \%$ \\
$31-40$ years & 27 & $35.1 \%$ \\
$41-50$ years & 18 & $24.3 \%$ \\
Above 51 years & 3 & $3.9 \%$ \\
The total & 77 & $100 \%$ \\
\hline
\end{tabular}

Table 4 shows that the highest percentage for distributing the individuals of the study according to variable of experience $(37.7 \%)$ for the category (3-5) years, and then (33.8\%) for (6-10) years, next (19.5\%) for (above 10$)$ years. Whereas the lowest percentage was $(9.1 \%)$ for (lower than 2 ) years.

Table 4. Distributing the individuals of the study according to experience

\begin{tabular}{lll}
\hline Experience & Frequency & Percentage \\
\hline Lower than 2 years & 7 & $9.1 \%$ \\
3-5 years & 29 & $37.7 \%$ \\
6-10 years & 26 & $33.8 \%$ \\
Above 10 years & 15 & $19.5 \%$ \\
Total & 77 & $100 \%$ \\
\hline
\end{tabular}


Table 5 shows that the highest percentage for distributing the individuals of the study according to variable of scientific qualification (46.8\%) for the category (bachelor), and then $(24.7 \%)$ for (diploma), next $(23.7 \%)$ for (higher studies). Whereas the lowest percentage was (5.2\%) for (under secondary stage).

Table 5. Distributing the individuals of the sample according to scientific qualification

\begin{tabular}{lll}
\hline Scientific qualification & frequency & Percentage \\
\hline Under secondary stage & 4 & $5.2 \%$ \\
Diploma & 19 & $24.7 \%$ \\
Bachelor & 36 & $46.8 \%$ \\
Higher studies & 18 & $23.4 \%$ \\
Total & 77 & $100 \%$ \\
\hline
\end{tabular}

Table 6 shows that the highest percentage for distributing the individuals of the study according to variable of managerial level (36.4\%) for the category (worker), and then (24.7\%) for (head of department), next (22.1\%) for (supervisor). Whereas the lowest percentage was $(5.2 \%)$ for (other).

Table 6. Distributing the individuals of the sample according to managerial level

\begin{tabular}{lll}
\hline Managerial level & frequency & Percentage \\
\hline Worker & 28 & $36.4 \%$ \\
Supervisor & 17 & $22.1 \%$ \\
The head of department & 19 & $43.7 \%$ \\
Manager & 9 & $11.7 \%$ \\
Other & 4 & $5.2 \%$ \\
Total & 77 & $100 \%$ \\
\hline
\end{tabular}

\subsubsection{Examining the Hypothesis of the Study}

The first hypothesis: there is a statically significant at $(\alpha=0.05)$ between the management of creativity and successfulness of learning organizations:

To verify from the first hypothesis, the means, standard deviation and the total have been calculated. Also, "One Sample T-test" has been applied. Tables $(7 \& 8)$ show:

Table 7 shows that the mean of "the relation between creativity management and successfulness of the organizations" was (3.74). The highest mean was (3.94) for paragraph (1) "If the organization is interested in learning does it confirm with it is interested in creativity" and then paragraph (5) "Creativity and Excellency are indicators for successfulness of organization" and the mean was (3.92). After that, paragraph (2) "Learning effects on creativity and the performance of organization positively" and the mean was (3.82). Whereas, the lowest mean was (3.45) for paragraph (4) "Creativity develops productivity and competition in the different organizations".

Table 7. Means, standard deviation, and the total for the paragraph of creativity management and successfulness of the learning organizations

\begin{tabular}{llll}
\hline No. & Paragraph & Mean & Std. \\
\hline $\mathbf{1}$ & If the organization is interested in learning does it confirm with it is interested in creativity. & 3.94 & 1.13 \\
$\mathbf{2}$ & Learning effects on creativity and the performance of organization positively. & 3.82 & 1.00 \\
$\mathbf{3}$ & If the learning the main aim of the organization is learning and development so it will be an & 3.58 & 1.21 \\
& evidence that it is an creative organization. & 3.45 & 1.23 \\
$\mathbf{4}$ & Creativity develops productivity and competition in the different organizations & 3.92 & 1.12 \\
$\mathbf{5}$ & Creativity and Excellency are indicators for successfulness of organization. & $\mathbf{3 . 7 4}$ & $\mathbf{0 . 5 6}$ \\
The total/ the relation between creativity management and successfulness of the organizations.
\end{tabular}

Table 8 shows that $(\mathrm{T})$ for the field was (11.564) and it is a statically significant at $(\alpha=0.05)$ and standard mark was (3). Mean was (3.74) and it is the higher than the value of the standard mark, that indicates for statically 
significant $(\alpha=0.05)$ between creativity management and successfulness of learning organizations. So, the hypothesis was accepted.

Table 8 . The results of (one sample t-test) on the field of the relation between creativity management and successfulness of learning organizations

\begin{tabular}{lllllll}
\hline The filed & & Mean & T & DF & Sig. & Result \\
\hline $\begin{array}{l}\text { The relation between creativity management } \\
\text { successfulness of learning organizations. }\end{array}$ & and & 3.74 & 11.564 & 76 & 0.00 & Accepted \\
\hline
\end{tabular}

The second hypothesis: there is statically significant $(\alpha=0.05)$ between creativity management and the availability of learning organizations elements.

To verify from the hypothesis, mean, standard deviation and the total have been calculated. MNOVA was applied between the elements of establishing the organizations and the field of creativity management. Table ( $9 \& 10)$ show:

Table 9 shows that the mean of the field the "personal empowering" was (3.94). The highest mean was (4.17) for paragraph (1) "I have ability to tolerate pressure of the work and the whatever job "and then paragraph (4) "I try to develop myself always in the continuous learning through looking at what is new "and the mean was (4.00). After that, paragraph (2) "I have the technological knowledge to achieve any work of mine "and the mean was (3.99). Whereas, the lowest mean was (3.62) for paragraph (3) "My own aims are separated in my work and my job".

Table 9. Means, standard deviation and the total for the paragraphs the personal empowering

\begin{tabular}{llll}
\hline No. & Paragraph & Mean & Std. \\
\hline $\mathbf{1}$ & I have ability to tolerate pressure of the work and the whatever job. & 4.17 & 0.94 \\
$\mathbf{2}$ & I have the technological knowledge to achieve any work of mine. & 3.99 & 0.91 \\
$\mathbf{3}$ & My own aims are separated in my work and my job. & 3.62 & 1.23 \\
$\mathbf{4}$ & I try to develop myself always in the continuous learning through looking at what is new. & 4.00 & 1.01 \\
The field as a whole/ the personal empowering. & $\mathbf{3 . 9 4}$ & $\mathbf{0 . 6 8}$ \\
\hline
\end{tabular}

Table 10 shows that the mean of the field the "common vision" was (3.58). The highest mean was (3.82) for paragraph (1) "I cooperate my friends to complete the work correctly. "and then paragraph (2)" I involve with my friends to achieve the objectives and the visions " and the mean was (3.74). After that, paragraph (3) "I tolerate with my friends for any negative results sustained the company "and the mean was (3.52). whereas, the lowest mean was (3.26) for paragraph (4) "The company tries to adopt the employers ideas and tries to develop them".

Table 10. Mean, standard deviation and the total for all paragraphs of the field: the common vision

\begin{tabular}{llll}
\hline No. & Paragraph & Mean & Std. \\
\hline $\mathbf{1}$ & I cooperate my friends to complete the work correctly. & 3.82 & 1.13 \\
$\mathbf{2}$ & I involve with my friends to achieve the objectives and the visions. & 3.74 & 1.02 \\
$\mathbf{3}$ & I tolerate with my friends for any negative results sustained the company. & 3.52 & 1.15 \\
$\mathbf{4}$ & The company tries to adopt the employers ideas and tries to develop them. & 3.26 & 1.17 \\
The field as a whole/ the common vision & $\mathbf{3 . 5 8}$ & $\mathbf{0 . 7 7}$ \\
\hline
\end{tabular}

Table 11 shows that the mean of the field "the mental vision "was (3.75). The highest mean was (4.03) for paragraph (1) "I try to analyze the matters related to the work practically" and then paragraph (2) "I try to shorten the procedures of my work and my job to make others understand it easily" and the mean was (3.88). after that, paragraph (3) "I seek to judge on other freely " and the mean was (3.65). Whereas, the lowest mean was (3.44) for paragraph (4) "My thoughts and ideas are translation of my institution and its vision". 
Table 11. Means, standard deviation and the total for all paragraphs of the field of the mental patterns

\begin{tabular}{llll}
\hline No. & Paragraph & Mean & Std. \\
\hline 1 & I try to analyze the matters related to the work practically. & 4.03 & 1.01 \\
2 & I try to shorten the procedures of my work and my job to make others understand it easily. & 3.88 & 0.95 \\
3 & I seek to judge on other freely. & 3.65 & 0.96 \\
4 & My thoughts and ideas are translation of my institution and its vision. & 3.44 & 1.32 \\
The field as a whole/ the mental patterns & 3.75 & 0.63 \\
\hline
\end{tabular}

Table 12 shows that the mean of the field "learning the difference" was (3.66). The highest mean was (3.87) for paragraph (1) "We utilize our trials and work as a whole team. "and then paragraph (3) "I and my friends depend on the conversation through providing my thought and accept their thoughts " and the mean was (3.74). After that, paragraph (4) "I and my friends discuss the details of work to be cleared "and the mean was (3.56). Whereas, the lowest mean was (3.48) for paragraph (2) "There is no individualism in the firm during decisionmaking by the responsible".

Table 12. Mean, standard deviation and the total for all paragraph on the field of "learning the difference"

\begin{tabular}{llll}
\hline No. & Paragraph & Mean & Std. \\
\hline $\mathbf{1}$ & We utilize our trials and work as a whole team. & 3.87 & 1.13 \\
$\mathbf{2}$ & There is no individualism in the firm during decision- making by the responsible. & 3.48 & 1.15 \\
$\mathbf{3}$ & I and my friends depend on the conversation through providing my thought and accept their & 3.74 & 1.19 \\
& thoughts. & 3.56 & 1.32 \\
$\mathbf{4}$ & I and my friends discuss the details of work to be cleared. & $\mathbf{3 . 6 6}$ & $\mathbf{0 . 7 7}$ \\
The field as a whole/ learning the difference.
\end{tabular}

Table 13 shows that the mean of the field "organizational thinking" was (3.68). The highest mean was (3.87) for paragraph (2) "I understand how my work connect with the work of others and its effect on them". And then paragraph (1) "We treat any working problems through providing group and not individual solutions and the mean was (3.75). After that, paragraph (3) "I accept any notes on my work and try to utilize them" and the mean was (3.70). Whereas, the lowest mean was (3.38) for paragraph (4) "We as friends and management share in developing the work and make the procedures easily".

Table 13. Means, standard deviation and the total for all the paragraphs of the field of "the organizational thinking"

\begin{tabular}{llll}
\hline No. & Paragraph & Mean & Std. \\
\hline $\mathbf{1}$ & We treat any working problems through providing group and not individual solutions. & 3.75 & 1.22 \\
$\mathbf{2}$ & I understand how my work connect with the work of others and its effect on them. & 3.87 & 3.70 \\
$\mathbf{3}$ & I accept any notes on my work and try to utilize them. & 1.274 \\
$\mathbf{4}$ & We as friends and management share in developing the work and make the procedures & 3.38 & 1.09 \\
& easily. & $\mathbf{3 . 6 8}$ & $\mathbf{0 . 7 0}$ \\
The field as a whole/ the organizational thinking &
\end{tabular}

Table 14 shows that the mean of the field "creativity" was (3.35). The highest mean was (3.70) for paragraph (2)" I involve in the training and conferences the conduct in and out the firm "and then paragraph (4)" The annual reports are affected by the activities of the employers "and the mean was (3.32). After that, paragraph (3) "The firm urges on creativity continuously and it develops for the soul of initiatives for the employers and the mean was (3.26)". Whereas, the lowest mean was (3.13) for paragraph (1) "The management of the firm rewards the talented and the innovators at work. 
Table 14. Means, standard deviation, and the total in all paragraphs of the field of creativity

\begin{tabular}{llll}
\hline No. & Paragraph & Mean & Std. \\
\hline $\mathbf{1}$ & The management of the firm rewards the talented and the innovators at work. & 3.13 & 1.40 \\
$\mathbf{2}$ & I involve in the training and conferences the conduct in and out the firm & 3.70 & 1.08 \\
$\mathbf{3}$ & The firm urges on creativity continuously and it develops for the soul of initiatives for the & 3.26 & 1.32 \\
& employers. & 3.32 & 1.26 \\
$\mathbf{4}$ & The annual reports are affected by the activities of the employers. & $\mathbf{3 . 3 5}$ & $\mathbf{0 . 8 4}$ \\
The field as a whole/ the field of creativity
\end{tabular}

Table 15 shows that $(R)$ reached $(0.54)$, it is a high value and it indicated that there is a huge regression between creativity management and the elements of learning organizations. (R-square) was $(0.29)$, it is a high value between the ability of creativity management on the elements of learning organization. $(F)$ reached (5.994), it is statically significant $(\alpha=0.05)$, and that indicates a statically significant for the effect of creativity on the elements of learning organization. The results have shown that creativity has an effect on the common vision, and $(\beta)$ was $(0.21)$.

Table 15. The results of (Multiple Regression) to study the impact of creativity management on the availability of the elements of learning organizations

\begin{tabular}{llllllll}
\hline Variable & $\beta$ value & T- value & Sig. & R & R-square & F- value & Level of Sig. \\
\hline Personal empowering. & 0.03 & 0.28 & 0.78 & & & & \\
The common vision. & 0.21 & 1.26 & 0.10 & & & & \\
The mental patterns. & 0.09 & 0.68 & 0.49 & 0.54 & 0.29 & 5.994 & 0.00 \\
Learning the differences . & 0.18 & 0.17 & 0.24 & & & & \\
The organizational thinking. & 0.14 & 1.04 & 0.29 & & & & \\
\hline
\end{tabular}

In the light of the results of the hypothesis have shown that there is a relation between creativity management and the elements of learning organization. So the third hypothesis is accepted and the other rejected.

The third hypothesis: there is a difference in the thoughts of samples individuals about the effect of creativity management in the learning organizations according to variables of (experience, scientific qualification, and managerial level):

To verify from the third hypothesis, means, standard deviations of the tool as a whole according to variables of (experience, scientific qualification, and managerial level) have been calculated. (ANOVA) was applied according to variables of (experience, scientific qualification, and managerial level). Tables (16-18) show:

Table 16 shows that there is no difference in the thoughts of sample individuals about the impact of creativity on the learning organizations according to variable of experience. $(F)$ reached $(1.561)$, it is nor statically significant $(\alpha=0.05)$.

Table 16. The results of applying (ANOVA) on the tool as a whole according to variable of experience

\begin{tabular}{lllll}
\hline Experience & Mean & Std. & F & Sig. \\
\hline Less than 2 years . & 3.46 & 0.33 & & \\
3-5 years . & 3.64 & 0.54 & & \\
6-10 years. & 3.64 & 0.54 & 1.561 & 0.20 \\
More than 10 years. & 3.91 & 0.42 & & \\
\hline
\end{tabular}

Table 17 shows that there is no difference in the thoughts of sample individuals about the impact of creativity on the learning organizations according to variable of scientific qualification. (F) reached (0.503), it is not statically significant $(\alpha=0.05)$. 
Table 17. The results of applying (ANOVA) on the tool as a whole according to variable of scientific qualification

\begin{tabular}{lllll}
\hline Experience & Mean & Std. & F & Sig. \\
\hline Less than secondary & 3.75 & 0.51 & & \\
Diploma & 3.76 & 0.31 & 0.503 & 0.68 \\
Bachelor & 3.60 & 0.60 & & \\
Higher studies & 3.72 & 0.50 & & \\
\hline
\end{tabular}

Table 18 shows that there is no difference in the thoughts of sample individuals about the impact of creativity on the learning organizations according to variable of managerial level. $(F)$ reached (1.792), it is not statically significant $(\alpha=0.05)$.

Table 18. The results of applying (ANOVA) on the tool as a whole according to the managerial level

\begin{tabular}{lllll}
\hline Experience & Mean & Std. & F & Sig. \\
\hline worker & 3.53 & 0.55 & & \\
Supervisor & 3.62 & 0.48 & 1.792 & 0.14 \\
Head of department & 3.77 & 0.50 & & \\
Manager & 3.87 & 0.40 & & \\
Other & 4.07 & 0.26 & & \\
\hline
\end{tabular}

\section{The Results}

After conducting the statically analysis for the answers of sample individuals and they were (77) employers from both genders from the community of the study, it has been in the following results:

- There is a statically significant at $(\alpha=0.05)$ between creativity management and successfulness of learning organization.

- There is a statically significant at $(\alpha=0.05)$ between creativity management and the availability of establishing the learning organization elements.

- There are no differences in thoughts of sample individuals about the impact of creativity management in the learning organizations according to: (experience, scientific qualification, and the managerial level).

\section{Recommendations}

In the light of mentioned results, the study has recommended with the following suggestions:

- Encouraging the learning organizations on competition and developing the spirit of creativity and productivity.

- Encouraging the employers of the learning organizations to introduce improving ideas to develop the institutions.

- Involving with the employers in making decisions at the learning organizations.

- Setting a rewarding system by the management of the firm for the talented and innovators at the work.

- Conducting similar studies on a bigger sample including the majority of the employers of the learning organization in Jordan to identify the impact of creativity.

\section{References}

Abu, L. H. (2007). Impediments to the creative process in the small and medium business organizations in Jordan. Master Thesis, creativity books Center, University of Jordan, Amman.

Alqbise, S. (2002). The reality of management innovation in the government of the Emirate of Abu Dhabi circuit. Master Thesis, University of Jordan, Amman, Jordan.

Benran, H. S. (2010). Knowledge Management and Leadership Development. Retrieved from http://www.journal.cybrarans.info/index.php?option-com

Bkar, B. (2003). Innovation management in learning organizations (unpublished Master Thesis). Yarmouk University, Irbid, Jordan.

Du, R. Ai, S., \& Ren, Y. (2007). Relationship between Knowledge Sharing and Performance: A Survey in Xi'an, 
China. Expert Systems with Application, 32, 38-46.

Fa'ouri, A. (2010). A supportive environment to share knowledge: An Empirical Study on the telecommunications sector in Jordan. Jordan Journal of Business Management, 5(3), 223-326.

Hsu, M., Ju, T., Yen, C., \& Change, C. (2007). The Effect of Innovation About Occupation Organization. Int. J. Human-Computer Studies, 65, 153-169.

Hyjan, A. R. (1999). Obstacles to innovation organizations in Saudi Arabia. Journal of Public Administration, $39(1), 1-69$.

Krasna, A. F. (2009). Knowledge and information management: International experiences, study the information (3rd ed.).

Law, C. C. H., \& Nagi, E. W. T. (2008). The Innovation and Jobs Improvement. An International Journal, 34(4), 2342-2349.

Lin, W. B. (2008). The Effects of Innovation on Reaction Organizations Unit. International Journal, 34(2), 1508-1521.

Najem, A. (2005). Measurement and evaluation of cognitive labor productivity in specialized companies and knowledge-based.

Rashid, M. (2004). The social aspect of creativity. Institute of Public Administration, 44(1).

Senge, P. (2007). The Fifth Discipline the Art and Practice of the Learning Organization. Random House: Business Books, UK.

Yang, J. (2009). Innovation and Worker. International Journal of Selection and Assessment, 7(2), 97-111.

\section{Copyrights}

Copyright for this article is retained by the author(s), with first publication rights granted to the journal.

This is an open-access article distributed under the terms and conditions of the Creative Commons Attribution license (http://creativecommons.org/licenses/by/3.0/). 